\title{
The changing treatment landscape in idiopathic pulmonary fibrosis
}

\author{
Ulrich Costabel
}

Affiliation: Interstitial and Rare Lung Disease Unit, Ruhrlandklinik, University Hospital, University DuisburgEssen, Essen, Germany.

Correspondence: Ulrich Costabel, Ruhrlandklinik, Tüschener Weg 40, 45239 Essen, Germany.

E-mail: ulrich.costabelaruhrlandklinik.uk-essen.de

ABSTRACT Idiopathic pulmonary fibrosis (IPF) is a chronic, progressive and irreversible fibrotic disease of the lung that has greatly frustrated clinicians for a long time. The prognosis of IPF (median survival 2-5 years following diagnosis) is poorer than that of some cancers and for many years no significant advances were made in its management. However, between 2011 and 2014 a number of pivotal developments were made that have improved the outlook for patients with IPF. Herein, we review this rapidly changing landscape, discussing key events whilst still acknowledging that IPF remains a challenging disease to diagnose and manage.

@ERSpublications

Idiopathic pulmonary fibrosis has become a treatable disease, with two drugs now approved for this indication http://ow.ly/GhCEE

\section{Introduction}

Idiopathic pulmonary fibrosis (IPF) is a rare, chronic, progressive, irreversible and usually fatal disease, marked by progressive dyspnoea and, ultimately, respiratory failure $[1,2]$. IPF predominantly affects elderly male smokers/ex-smokers with a median age at diagnosis of 65-70 years [3]. Although it is a rare disease, with an estimated prevalence range of 1-23 cases per 100000 European persons [4-9], IPF represents a considerable challenge for clinicians. This is due to its poor prognosis (median survival of 2-5 years following diagnosis) $[1,2,10-12]$ and the fact that, until relatively recently, no clinically proven or approved pharmacological treatment has been available. Lung transplantation, which is potentially curative, is only available to a small minority of IPF patients $[1,13]$.

Significant research has been conducted over the past decade in the hope of finding a treatment that can slow disease progression and potentially improve survival. This is now becoming a reality, and between 2011 and 2014 a veritable raft of new study results have furthered our understanding of the disease and transformed the bleak outlook for IPF patients into one of hope [14-18]. Herein, we review this rapidly changing landscape, discussing the pivotal events that occurred between 2011 and 2014, whilst still acknowledging that IPF remains a challenging disease to diagnose and manage.

The dynamic treatment and management landscape in IPF: 2011-2014

2011: updated guidelines and approval of the first pharmacological treatment for IPF in Europe

A key turning point in the diagnosis, management and treatment of IPF occurred in late 2010 and 2011 when the American Thoracic Society (ATS)/European Respiratory Society (ERS)/Japanese Respiratory Society/Latin American Thoracic Association revised guidelines for IPF diagnosis and management were finalised and published [1]. These guidelines represented a significant advancement on the 2000 ATS/ERS

Received: Nov 212014 | Accepted after revision: Dec 132014

Conflict of interest: Disclosures can be found alongside the online version of this article at err.ersjournals.com

Provenance: Publication of this peer-reviewed article was supported by InterMune International AG, Muttenz, Switzerland (article sponsor, European Respiratory Review issue 135).

Copyright OERS 2015. ERR articles are open access and distributed under the terms of the Creative Commons Attribution Non-Commercial Licence 4.0. 
guidelines [19], most notably in clarifying and fine tuning diagnostic criteria. However, at the time of publication, the guidelines did not provide a positive recommendation for any pharmacological treatment for patients with chronic IPF, while there was a weak positive recommendation for steroids in cases of acute exacerbation [1].

Also in 2010, the European Medicines Agency (EMA) approved pirfenidone, the first pharmacological treatment available to patients with mild-to-moderate IPF [20]. The EMA's approval was based on the results of three phase III, randomised controlled trials (one Japanese and two multinational), only two of which reached the primary end-point. This led the US Food and Drug Administration (FDA) to request that an additional trial be conducted before granting pirfenidone approval in the USA [14]. During 2011 and 2012, two other important studies also helped shape the treatment landscape. Interim analysis from the National Institutes of Health-sponsored IPF-PANTHER study indicated that triple therapy with prednisone, azathioprine and $\mathrm{N}$-acetylcysteine (NAC) is potentially harmful to patients with IPF, significantly changing clinical practice at the time [16]. However, the study continued to evaluate NAC as monotherapy [21]. The AntiCoagulant Effectiveness in Idiopathic Pulmonary Fibrosis study, published in 2012, also demonstrated that anticoagulant therapy was of no benefit and was potentially harmful in IPF [17].

\section{1-2014: long-term and real-world experience in the treatment of IPF with pirfenidone}

Since the approval of pirfenidone in 2011 by the EMA, important data on the use of pirfenidone from clinical studies, long-term observational studies and real-world practice has been accumulated, demonstrating that pirfenidone significantly reduces forced vital capacity (FVC) decline and slows disease progression in IPF [22-30]. These longer term studies also showed that pirfenidone is generally well tolerated. The most common adverse events associated with treatment are gastrointestinal (nausea, diarrhoea and vomiting) and skin related (rash and photosensitivity) [14, 15, 20,31]. These events have primarily been mild to moderate in severity and relatively simple measures, such as taking the drug with food, reducing exposure to sunlight and managing patient expectations, have been shown to mitigate these adverse events. This has helped to encourage adherence, ensuring the long-term benefits of treatment [32].

\section{4: first treatments approved in the USA and evidence for improved survival with pirfenidone}

2014 has witnessed a number of significant events in the development of IPF treatment and research. For the first time, treatments for IPF have been approved in the USA. On October 15, 2014, both pirfenidone and nintedanib received approval from the US FDA [33]. The US FDA approval of pirfenidone was based on a third multinational trial involving pirfenidone, the ASCEND (Assessment of Pirfenidone to Confirm Efficacy and Safety in IPF) trial, which had been requested by the US FDA and has been published recently [14]. ASCEND reinforced the evidence of efficacy and safety shown in previous trials, demonstrating that pirfenidone significantly reduced disease progression as measured by change in FVC \% predicted from baseline at 1 year compared to placebo [14]. As requested by the US FDA, a pre-specified pooled analysis involving patients from the ASCEND trial and the two phase III CAPACITY (Clinical Studies Assessing Pirfenidone in Idiopathic Pulmonary Fibrosis: Research an Efficacy and Safety Outcomes) studies ( $\mathrm{n}=1247)$ showed that the risk of all-cause mortality and treatment-emergent IPF-related mortality after 1 year was significantly reduced by $48 \%$ and $68 \%$, respectively, in the pirfenidone group compared to the placebo group [14].

The INPULSIS trials, published at the same time as the ASCEND trial, also showed that nintedanib, a small molecule tyrosine kinase inhibitor, reduced FVC decline in IPF to a similar extent as pirfenidone. While there were numerically fewer deaths in the nintedanib arm compared to placebo, this difference did

TABLE 1 Idiopathic pulmonary fibrosis treatment: a dynamic field since 2011

20112014

Pirfenidone approved

by EMA

Triple therapy out

Anticoagulants out
Pirfenidone approved by the US FDA: evidence on efficacy and safety observed in previous studies reinforced (ASCEND trial) [33]

Nintedanib approved by the US FDA [33], CHMP of EMA positive opinion: second antifibrotic drug with positive effects in two phase III trials (INPULSIS trials) [34]

NAC monotherapy out (PANTHER trial) [21]

EMA: European Medicines Agency; FDA: Food and Drug Administration; ASCEND: Assessment of Pirfenidone to Confirm Efficacy and Safety in IPF; CHMP: Committee for Medicinal Products for Human Use; NAC: $\mathrm{N}$-acetylcysteine. 
not reach statistical significance (nintedanib group: HR 0.70 (95\% CI $0.43-1.12$ ), p=0.14) [18]. The final results of the PANTHER trial showed that NAC monotherapy had no significant benefit in the preservation of FVC [21]. However, flaws in the study conduct do not allow us to conclude definitively that NAC has no role in IPF (table 1).

\section{Looking towards the future: ongoing challenges in IPF}

While we have experienced significant breakthroughs in our understanding and treatment of IPF in the past few years, many challenges remain. In particular, identifying suspected IPF patients for early diagnosis and treatment, and managing treatment tolerability in these patients for successful adherence over the long term in order to potentially change the disease course. Other unresolved issues include how to manage treatment for patients with probable or possible IPF who do not fulfil all criteria for definite IPF and patients with severe IPF who, in Europe, do not qualify for treatment with pirfenidone.

Early diagnosis remains a challenge and requires a multidisciplinary approach. Thorough patient history and clinical examination coupled with interpretation of high-resolution computed tomography is necessary for all patients. The convergence of knowledge and expertise from the physician, thoracic radiologist and pathologist is critical to increase the chance of an accurate diagnosis [34]. International, evidence-based guidelines now emphasise the importance of a multidisciplinary team approach in the diagnosis and management of IPF [1]. Promising genetic markers (e.g. MUC5B) may improve the clinical management of IPF patients in the future [35].

Combination therapy consisting of antifibrotic drugs with different mechanisms of action will probably gain increasing importance in the future. To this end, appropriately controlled trials evaluating monotherapy versus combination therapy must be undertaken and demonstrate the superiority of the combination over the single agent [36]. With earlier diagnosis and the initiation of treatment with proven effective therapies, we are now in a position to be more optimistic about altering the course of IPF. Within a few short years we have seen real victories against a disease that was considered to have a prognosis as hopeless as some of the more difficult cancers. We have every reason to believe that the success in slowing the progression of IPF will continue to bring hope to more IPF patients.

\section{Acknowledgements}

This article is based on the proceedings of a satellite symposium held at the 2014 ERS International Congress (Munich, Germany), which was sponsored by InterMune Inc. The author was assisted in the preparation of the text by professional medical writers at IntraMed International (Milan, Italy). The medical writing support was funded by InterMune International AG (Muttenz, Switzerland).

\section{References}

1 Raghu G, Collard HR, Egan JJ, et al. An official ATS/ERS/JRS/ALAT statement: idiopathic pulmonary fibrosis: evidence-based guidelines for diagnosis and management. Am J Respir Crit Care Med 2011; 183: 788-824.

2 Ley B, Collard HR, King TE Jr. Clinical course and prediction of survival in idiopathic pulmonary fibrosis. Am J Respir Crit Care Med 2011; 183: 431-440.

3 Cordier JF, Cottin V. Neglected evidence in idiopathic pulmonary fibrosis: from history to earlier diagnosis. Eur Respir J 2013; 42: 916-923.

4 Gribbin J, Hubbard RB, Le Jeune I, et al. Incidence and mortality of idiopathic pulmonary fibrosis and sarcoidosis in the UK. Thorax 2006; 61: 980-985.

5 Hodgson U, Laitinen T, Tukiainen P. Nationwide prevalence of sporadic and familial idiopathic pulmonary fibrosis: evidence of founder effect among multiplex families in Finland. Thorax 2002; 57: 338-342.

6 Karakatsani A, Papakosta D, Rapti A, et al. Epidemiology of interstitial lung diseases in Greece. Respir Med 2009; 103: $1122-1129$.

7 Navaratnam V, Fleming KM, West J, et al. The rising incidence of idiopathic pulmonary fibrosis in the UK. Thorax 2011; 66: 462-467.

8 Thomeer MJ, CostabeL U, Rizzato G, et al. Comparison of registries of interstitial lung diseases in three European countries. Eur Respir J 2001; 18: Suppl. 32, 114s-118s.

9 von Plessen C, Grinde O, Gulsvik A. Incidence and prevalence of cryptogenic fibrosing alveolitis in a Norwegian community. Respir Med 2003; 97: 428-435.

10 Collard HR, Moore BB, Flaherty KR, et al. Acute exacerbations of idiopathic pulmonary fibrosis. Am J Respir Crit Care Med 2007; 176: 636-643.

11 Kim DS, Collard HR, King TE Jr. Classification and natural history of the idiopathic interstitial pneumonias. Proc Am Thorac Soc 2006; 3: 285-292.

12 Meltzer EB, Noble PW. Idiopathic pulmonary fibrosis. Orphanet J Rare Dis 2008; 3: 8.

13 Meyer C, Nathan SD. Idiopathic Pulmonary Fibrosis: a Comprehensive Clinical Guide. Totowa, NJ, Humana Press, 2013.

14 King TE Jr, Bradford WZ, Castro-Bernardini S, et al. A phase 3 trial of pirfenidone in patients with idiopathic pulmonary fibrosis. N Engl J Med 2014; 370: 2083-2092.

15 Noble PW, Albera C, Bradford WZ, et al. Pirfenidone in patients with idiopathic pulmonary fibrosis (CAPACITY): two randomized trials. Lancet 2011; 377: 1760-1769.

16 National Institutes of Health. Commonly used three-drug regimen for idiopathic pulmonary fibrosis found harmful. Press Release October 21, 2011. www.nih.gov/news/health/oct2011/nhlbi-21.htm 
17 Noth I, Anstrom KJ, Calvert SB. A placebo-controlled randomized trial of warfarin in idiopathic pulmonary fibrosis. Am J Respir Care Med 2012; 186: 88-95.

18 Richeldi L, du Bois RM, Raghu G, et al. Efficacy and safety of nintedanib in idiopathic pulmonary fibrosis. $N$ Engl J Med 2014; 370: 2071-2082.

19 American Thoracic Society. Idiopathic pulmonary fibrosis: diagnosis and treatment: international consensus statement. American Thoracic Society (ATS), and the European Respiratory Society (ERS). Am J Respir Crit Care Med 2000; 161: 646-664.

20 European Medicines Agency. CHMP assessment report EMA/CHMP/115147/2011 www.ema.europa.eu/docs/en GB/document_library/EPAR_Public_assessment_report/human/002154/WC500103073.pdf Date last updated: December 16, 2010. Date last accessed: November 19, 2014.

21 Idiopathic Pulmonary Fibrosis Clinical Research Network, Martinez FJ, de Andrade JA, et al. Randomized trial of acetylcysteine in idiopathic pulmonary fibrosis. N Engl J Med 2014; 370: 2093-2101.

22 Costabel U, Albera C, Bradford WZ, et al. Analysis of lung function and survival in RECAP: an open-label extension study of pirfenidone in patients with idiopathic pulmonary fibrosis. Sarcoidosis Vasc Diffuse Lung Dis 2014; 31: 198-205.

23 Chaudhuri N, Duck A, Frank R, et al. Real world experiences: pirfenidone is well tolerated in patients with idiopathic pulmonary fibrosis. Respir Med 2014; 108: 224-226.

24 Bonella F, Wessendorf TE, Costabel U. Klinische Erfahrungen mit Pirfenidon in der Therapie der idiopathischen Lungenfibrose [Clinical experience with pirfenidone for the treatment of idiopathic pulmonary fibrosis]. Dtsch Med Wochenschr 2013; 138: 518-523.

25 Oltmanns U, Kahn N, Wenz H, et al. Pirfenidone in idiopathic pulmonary fibrosis: real-life experience from a German tertiary referral centre for interstitial lung diseases. Eur Respir J 2013; 42: Suppl. 57, p2335.

26 Okuda R, Hagiwara E, Baba T, et al. Safety and efficacy of pirfenidone in idiopathic pulmonary fibrosis in clinical practice. Respir Med 2013; 107: 1431-1437.

27 Arai $\mathrm{T}$, Inoue $\mathrm{Y}$, Sasaki $\mathrm{Y}$, et al. Predictors of the clinical effects of pirfenidone on idiopathic pulmonary fibrosis. Respir Investig 2014; 52: 136-143.

28 Ravaglia C, Gurioli C, Romagnoli M, et al. Pirfenidone treatment in idiopathic pulmonary fibrosis: an Italian case series. Eur Respir J 2013; 42: Suppl. 57, p3370.

29 Nieto Barbero MA, Valenzuela C, Rivera Ortega P, et al. Pirfenidone in idiopathic pulmonary fibrosis (IPF): early Spanish experience with the European named patient program (NPP). Eur Respir J 2013; 42: Suppl. 57, p2361.

30 Valeyre D, Albera C, Bradford WZ, et al. Comprehensive assessment of the long-term safety of pirfenidone in patients with idiopathic pulmonary fibrosis. Respirology 2014; 19: 740-747.

31 Annex I. Summary of Product Characteristics. www.ema.europa.eu/docs/en_GB/document library/EPAR - Product Information/human/002154/WC500103049.pdf Date last updated: October 2014. Date last accessed: November 19, 2014.

32 Costabel U, Bendstrup E, Cottin V, et al. Pirfenidone in idiopathic pulmonary fibrosis: expert panel discussion on the management of drug-related adverse events. Adver Ther 2014; 31: 375-391.

33 U.S. Food and Drug Administration. FDA approves Esbriet to treat idiopathic pulmonary fibrosis. www.fda.gov/ NewsEvents/Newsroom/PressAnnouncements/ucm418991.htm Date last updated: October 15, 2014. Date last accessed: November 19, 2014

34 Maher TM. A clinical approach to diffuse parenchymal lung disease. Immunol Allergy Clin North Am 2012; 32: 453-472.

35 Putman RK, Rosas IO, Hunninghake GM. Genetics and early detection in idiopathic pulmonary fibrosis. Am J Respir Crit Care Med 2014; 189: 770-778.

36 Wuyts WA, Antoniou KM, Borensztajn K, et al. Combination therapy: the future of management for idiopathic pulmonary fibrosis? Lancet Respir Med 2014; 2: 933-942. 